\title{
Thermal and mechanical properties of some fcc transition metals
}

\author{
T. Çă̆ın \\ Materials and Process Simulation Center, California Institute of Technology, Pasadena, California 91125 \\ G. Dereli, M. Uludoğan, and M. Tomak \\ Department of Physics, Middle East Technical University, 06531 Ankara, Turkey \\ (Received 4 September 1997; revised manuscript received 27 April 1998)
}

\begin{abstract}
The temperature dependence of thermodynamic and mechanical properties of six fcc transition metals $(\mathrm{Ni}$, $\mathrm{Cu}, \mathrm{Ag}, \mathrm{Au}, \mathrm{Pt}, \mathrm{Rh}$ ) are studied using molecular dynamics (MD) simulations. The structures are described at elevated temperatures by the force fields developed by Sutton and co-workers within the context of the tight binding approach. In these simulations the thermodynamic and mechanical properties are calculated in the temperature range between 0 to $1500 \mathrm{~K}$ using the statistical fluctuation expressions over the MD trajectories. [S0163-1829(99)00805-X]
\end{abstract}

\section{INTRODUCTION}

Theoretical and computational modeling is becoming increasingly important in the development of advanced high performance materials for industrial applications. Atomistic level understanding of the properties of fcc transition metals under various conditions is important in their technological applications. The potentials developed by Sutton and co-workers ${ }^{1,2}$ are tested in simulations of pure silver, gold, copper, nickel, platinum, and rhodium over a wide temperature range. Our computer simulation results for Pt-Rh alloys are presented elsewhere. ${ }^{3}$ The molecular dynamics (MD) algorithms that we use are based on the extended Hamiltonian formalism and the ordinary experimental conditions are simulated using the constant-pressure, constant-temperature (NPT) MD method.

Computer simulations on various model systems usually use simple pair potentials. On many occasions to account for the directionality of bonding, three body interactions are also employed. The interactions in real crystalline materials cannot be represented by simple pairwise interactions alone. Pure pairwise potential model gives the Cauchy relation between the elastic constants $C_{12}=C_{44}$, which is not the case in real metals. In these systems the electron density plays a dominant role in interactions and resulting physical properties. Therefore, many-body interactions should be taken into consideration in any study of metals and metal alloys. In simple $s p$-bonded metals, the interaction potentials may be derived from model pseudopotentials using the second order perturbation theory. We have developed interaction potentials along these lines, and utilized them to study the properties of simple alkali metal and alkali metal alloys in the past. ${ }^{4}$ However, for $d$-band metal and metal alloys the model pseudopotential approach should give way to newer techniques evolved over the past ten years to account for the many body effects. Among these approaches, the empirical many body potentials based on Norskov's effective medium theory, ${ }^{5}$ Daw and Baskes' embedded atom method, ${ }^{6}$ Finnis and Sinclair's ${ }^{7,8}$ empirical many body potentials, and more recently the many body potentials developed by Sutton and co-workers ${ }^{1,2}$ within the context of tight binding approach ${ }^{9}$ for fcc transition metals can be listed. Due to its mathematically simple power law form and fairly long range character, in recent years the Sutton-Chen (SC) potential has been widely used in simulations to study a range of problems. ${ }^{10-16}$ Recently, we applied this potential to study thermal properties of Pt, Rh, and Pt-Rh alloys. ${ }^{3}$

In this paper we present a comprehensive study of thermal and mechanical properties of fcc transition metals $(\mathrm{Ni}, \mathrm{Cu}$, $\mathrm{Ag}, \mathrm{Au}, \mathrm{Pt}, \mathrm{Rh}$ ) using a molecular dynamics method. In the following section we will describe briefly the Sutton-Chen form of empirical many body potentials used in this study and summarize the statistical expressions used in calculating thermal and mechanical properties and address the details of simulation procedures used in the study. Then in the following Sec. III, we will present and discuss the results obtained at temperatures ranging from $0-1500 \mathrm{~K}$ for each system.

\section{THE METHOD}

In the SC description the total potential energy of the metal is given as a sum of a pairwise repulsion term and a many-body density dependent cohesion term. The cohesion term supplies the description of short-range interactions to obtain a good description of surface relaxation, and the pairwise term gives a correct description of long-range interactions with a van der Waals tail. The total potential energy of the metal is given as follows:

$$
U_{\mathrm{tot}}=\sum_{i} U_{i}=\sum_{i} D\left[\frac{1}{2} \sum_{j \neq i} V\left(r_{i j}\right)-c_{i} \rho_{i}\right],
$$

where

$$
\begin{gathered}
V(r)=\left(\frac{a}{r}\right)^{n}, \\
\rho_{i}=\left(\sum_{j \neq i} \phi\left(r_{i j}\right)\right)^{1 / 2}, \\
\phi(r)=\left(\frac{a}{r}\right)^{m} .
\end{gathered}
$$


The Sutton-Chen potential parameters $D, c$, and $m$ and $n$ are optimized to fit to the $0 \mathrm{~K}$ properties such as the cohesive energy, zero pressure condition, and the bulk modulus of the fcc metals.

The functional form of the Sutton-Chen potential is fairly simple in comparison to embedded atom method potentials and is moderately long ranged. The last property makes this set especially attractive for surface and interface studies among others, since most of them are very short ranged (are fitted up to first or second nearest neighbor distances).

In the following the expressions specific to many body potentials which are used in our computations are presented. The many body force on atom $a$ along a direction $i(=x, y, z)$ is given as

$$
F_{i a}=-D\left(\sum_{b}^{*} u^{\prime}(r) \frac{r_{a b i}}{r_{a b}}-\frac{c_{a}}{2} \frac{\sum_{b}^{*} \phi^{\prime}(r)\left(r_{a b i} / r_{a b}\right)}{\rho_{a}}+\sum_{b}^{*} \frac{c_{b}}{2 \rho_{b}} \phi^{\prime}(r) \frac{r_{b a i}}{r_{b a}}\right),
$$

where ' denotes $\partial / \partial r$ and * signifies the exclusion of $a=b$ from the sums. The anisotropic stress tensor including the contribution from the many body potential is calculated from

$$
\Omega P_{i j}=\sum_{a} \frac{p_{a i} p_{a j}}{m_{a}}-\frac{D}{2} \sum_{a}\left(\sum_{b}^{*} u^{\prime}(r) \frac{r_{a b i} r_{a b j}}{r_{a b}}-c_{a} \frac{\sum_{b}^{*} \phi^{\prime}(r)\left(r_{a b i} r_{a b j} / r_{a b}\right)}{\rho_{a}}\right) .
$$

The potential energy contribution to the elastic constants, the hypervirial tensor $\chi_{i j k l}$, is given as

$$
\begin{aligned}
\Omega \chi_{i j k l}= & \frac{D}{2} \sum_{a}\left[\sum_{b}^{*}\left(u^{\prime \prime}-\frac{u^{\prime}}{r_{a b}}\right) \frac{r_{a b i} r_{a b j} r_{a b k} r_{a b l}}{r_{a b}^{2}}-c_{a} \frac{\sum_{b}^{*}\left(\phi^{\prime \prime}-\frac{\phi^{\prime}}{r_{a b}}\right)\left(r_{a b i} r_{a b j} r_{a b k} r_{a b l} / r_{a b}^{2}\right)}{\rho_{a}}\right. \\
& \left.+\frac{c_{a}}{2} \frac{\left[\sum_{b}^{*} \phi^{\prime}\left(r_{a b i} r_{a b j} / r_{a b}\right)\right]\left[\sum_{c}^{*} \phi^{\prime}\left(r_{a c k} r_{a c l} / r_{a c}\right)\right]}{\rho_{a}^{3}}\right] .
\end{aligned}
$$

In our computations at each concentration and at each temperature, first the zero strain state $h_{0}$ of the system is determined by performing constant temperature and constant stress simulations (NPT) at zero stress. This yields the reference shape and size matrix, $h_{0}$ in the Parrinello-Rahman formalism. In determining elastic constants this reference state is used in constant temperature constant volume simulations (NVE) of 50000 steps for each state point. The elastic constants are evaluated using the following statistical fluctuation formulas: ${ }^{17}$

$$
\begin{aligned}
C_{i j k l}^{T}= & -\frac{\Omega_{0}}{k_{B} T}\left(\left\langle P_{i j} P_{k l}\right\rangle-\left\langle P_{i j}\right\rangle\left\langle P_{k l}\right\rangle\right) \\
& +\frac{2 N k_{B} T\left(\delta_{i k} \delta_{j l}+\delta_{i l} \delta_{j k}\right)}{\Omega_{0}}+\left\langle\chi_{i j k l}\right\rangle,
\end{aligned}
$$

where angular brackets denote the averaging over time and $\Omega_{0}=\operatorname{det} h_{0}$ is the reference volume for the model system. The first term represents the contribution from the fluctuation of the microscopic stress tensor $P_{i j}$, the second term represents the kinetic energy contribution, and the third term is the Born term.

We use the program SIMULATOR developed by Çağın that employs state of the art MD algorithms based on extended Hamiltonian formalisms emerging from the works of
Anderson, ${ }^{18}$ Parinello and Rahman, ${ }^{19}$ Nosé, ${ }^{20}$ Hoover, ${ }^{21}$ and Çağın. ${ }^{22}$ A 500 atoms cubical system is used and the simulation started with atoms randomly distributed on a fcc lattice.The system is thermalized starting from $0 \mathrm{~K}$ to the target temperature using a constant enthalpy and constant pressure (NHP) ensemble by slowly heating while scaling velocities to increment the temperature of $1 \mathrm{~K} / \mathrm{step}$ over the specific number of steps depending on the target temperature. This is followed by strict velocity scaling at each target temperature. Then, NPT dynamics at this temperature for 20000 steps to calculate the volume, density and enthalpy of the system for each concentration is performed. The resulting zero strain averaged matrix $\left\langle h_{0}\right\rangle$ is used in calculating elastic constants

TABLE I. Sutton-Chen potential parameters for fcc metals.

\begin{tabular}{cccccc}
\hline \hline $\begin{array}{c}a \\
(\AA)\end{array}$ & $\begin{array}{c}c \\
\left(10^{-2} \mathrm{eV}\right)\end{array}$ & \multicolumn{1}{c}{$c$} & $m$ & $n$ & Metal \\
\hline 3.52 & 1.57070 & 39.432 & 6 & 9 & $\mathrm{Ni}$ \\
3.61 & 1.23820 & 39.432 & 6 & 9 & $\mathrm{Cu}$ \\
4.09 & 0.25415 & 144.410 & 6 & 12 & $\mathrm{Ag}$ \\
4.08 & 1.27930 & 34.408 & 8 & 10 & $\mathrm{Au}$ \\
3.92 & 1.98330 & 34.408 & 8 & 10 & $\mathrm{Pt}$ \\
3.80 & 0.49371 & 144.410 & 6 & 12 & $\mathrm{Rh}$ \\
\hline \hline
\end{tabular}


TABLE II. The density, enthalpy, potential energy, and volume of $\mathrm{Ni}, \mathrm{Cu}, \mathrm{Ag}, \mathrm{Au}, \mathrm{Pt}$, and $\mathrm{Rh}$ as obtained from NPT molecular dynamics simulations after 20000 steps. The number in parentheses is the corresponding experimental value at that temperature.

\begin{tabular}{|c|c|c|c|c|c|}
\hline & $\begin{array}{c}T \\
(\mathrm{~K})\end{array}$ & $\begin{array}{c}\rho \\
\left(\mathrm{g} / \mathrm{cm}^{3}\right)\end{array}$ & $\begin{array}{c}H \\
(\mathrm{~kJ} / \mathrm{mol})\end{array}$ & $\begin{array}{c}U \\
(\mathrm{~kJ} / \mathrm{mol})\end{array}$ & $\begin{array}{c}500 \times V_{0} \\
\left(\mathrm{~nm}^{3}\right)\end{array}$ \\
\hline \multirow{5}{*}{$\mathrm{Ni}$} & 0 & 8.9079 (8.968) & -428.27002 & -428.28244 & 5.470 \\
\hline & 300 & $8.7468(8.90)$ & -420.77492 & -424.51844 & 5.571 \\
\hline & 500 & 8.6327 & -415.54424 & -421.78116 & 5.645 \\
\hline & 750 & 8.4815 & -408.77260 & -418.12898 & 5.745 \\
\hline & 1000 & 8.3176 & -401.66660 & -414.13714 & 5.858 \\
\hline \multirow{5}{*}{$\mathrm{Cu}$} & 0 & $8.9296(9.018)$ & -337.51511 & -337.52744 & 5.908 \\
\hline & 300 & 8.7235 (8.912) & -330.03778 & -333.77963 & 6.048 \\
\hline & 500 & 8.5742 & -324.71396 & -330.95169 & 6.153 \\
\hline & 750 & 8.3717 & -317.73297 & -327.08560 & 6.302 \\
\hline & 1000 & 8.1334 & -310.01874 & -322.48972 & 6.486 \\
\hline \multirow{5}{*}{$\mathrm{Ag}$} & 0 & $10.5040(10.635)$ & -285.52283 & -285.53348 & 8.526 \\
\hline & 300 & $10.2710(10.49)$ & -277.95578 & -281.69931 & 8.719 \\
\hline & 500 & 10.1030 & -272.64944 & -278.88458 & 8.864 \\
\hline & 750 & 9.8755 & -265.69861 & -275.05511 & 9.068 \\
\hline & 1000 & 9.6191 & -258.25937 & -270.73138 & 9.310 \\
\hline \multirow{5}{*}{$\mathrm{Au}$} & 0 & $19.2840(19.488)$ & -364.67062 & -364.68301 & 8.480 \\
\hline & 300 & $18.8411(19.32)$ & -357.05188 & -360.79401 & 8.679 \\
\hline & 500 & 18.5168 & -351.69836 & -357.93332 & 8.831 \\
\hline & 750 & 18.0595 & -344.58054 & -353.93341 & 9.055 \\
\hline & 1000 & 17.4804 & -336.48160 & -348.95288 & 9.355 \\
\hline \multirow{10}{*}{$\mathrm{Pt}$} & 0 & 21.5086 & -565.39642 & -565.40894 & 7.530 \\
\hline & 300 & $21.1954(21.50)$ & -557.82990 & -561.57330 & 7.641 \\
\hline & 500 & 20.9757 & -552.62994 & -558.86822 & 7.722 \\
\hline & 700 & 20.7427 & -547.30029 & -556.03040 & 7.808 \\
\hline & 750 & 20.6825 & -545.93384 & -555.28748 & 7.831 \\
\hline & 900 & 20.4961 & -541.79657 & -553.02002 & 7.902 \\
\hline & 1000 & 20.3664 & -538.96735 & -551.43976 & 7.952 \\
\hline & 1100 & 20.2303 & -536.06519 & -549.78400 & 8.006 \\
\hline & 1300 & 19.9378 & -530.03790 & -546.25262 & 8.123 \\
\hline & 1500 & 19.5992 & -523.49762 & -542.20453 & 8.264 \\
\hline \multirow{10}{*}{$\mathrm{Rh}$} & 0 & 12.4547 & -554.75891 & -554.77136 & 6.860 \\
\hline & 300 & $12.3152(12.45)$ & -547.24719 & -550.99084 & 6.937 \\
\hline & 500 & 12.2184 & -542.09912 & -548.33862 & 6.992 \\
\hline & 700 & 12.1191 & -536.88055 & -545.61493 & 7.049 \\
\hline & 750 & 12.0937 & -535.56250 & -544.91638 & 7.064 \\
\hline & 900 & 12.0162 & -531.56805 & -542.78949 & 7.110 \\
\hline & 1000 & 11.9637 & -528.87659 & -541.34656 & 7.141 \\
\hline & 1100 & 11.9099 & -526.14417 & -539.86707 & 7.173 \\
\hline & 1300 & 11.7990 & -520.59625 & -536.80499 & 7.241 \\
\hline & 1500 & 11.6838 & -514.93768 & -533.62976 & 7.312 \\
\hline
\end{tabular}

over 50000 steps of NVE dynamics. A fifth-order Gear predictor-corrector algorithm is used in $\Delta t=2 \mathrm{fs}$. The Parrinello-Rahman piston mass parameter is chosen as $W$ $=400$ and in NPT runs the Nosé-Hoover parameter is set to $Q=100$. The interaction range of the potential is taken to be two lattice parameters. But the temperature effects are taken into consideration by extending the range by an additional distance of half a lattice parameter.
TABLE III. The linear expansion of $\mathrm{Ni}, \mathrm{Cu}, \mathrm{Ag}$, and $\mathrm{Au}$ as a function of temperature.

\begin{tabular}{lcccc}
\hline \hline & $T(\mathrm{~K})$ & 500 & 750 & 1000 \\
\hline $\mathrm{Ni}$ & This Work & 0.44 & 1.04 & 1.72 \\
& Experiment & 0.29 & 0.69 & 1.13 \\
\hline $\mathrm{Cu}$ & This Work & 0.58 & 1.40 & 2.42 \\
& Experiment & 0.34 & 0.82 & 1.36 \\
\hline $\mathrm{Ag}$ & This Work & 0.55 & 1.34 & 2.26 \\
& Experiment & 0.43 & 0.99 & 1.61 \\
\hline $\mathrm{Au}$ & This Work & 0.58 & 1.44 & 2.60 \\
& Experiment & 0.31 & 0.70 & 1.14 \\
\hline \hline
\end{tabular}

\section{RESULTS AND DISCUSSION}

The potential parameters for the metals simulated in this work are given in Table I. The results of NPT molecular dynamics simulations after 20000 steps are shown in Table II. These are density, enthalpy, potential energy, and volume of 500 atoms calculated at the temperature range 0 to 1500 $\mathrm{K}$. In obtaining these values the system is thermalized starting from $0 \mathrm{~K}$ to the target temperature using 2000 steps NHP simulations. We then performed another 20000 steps NPT

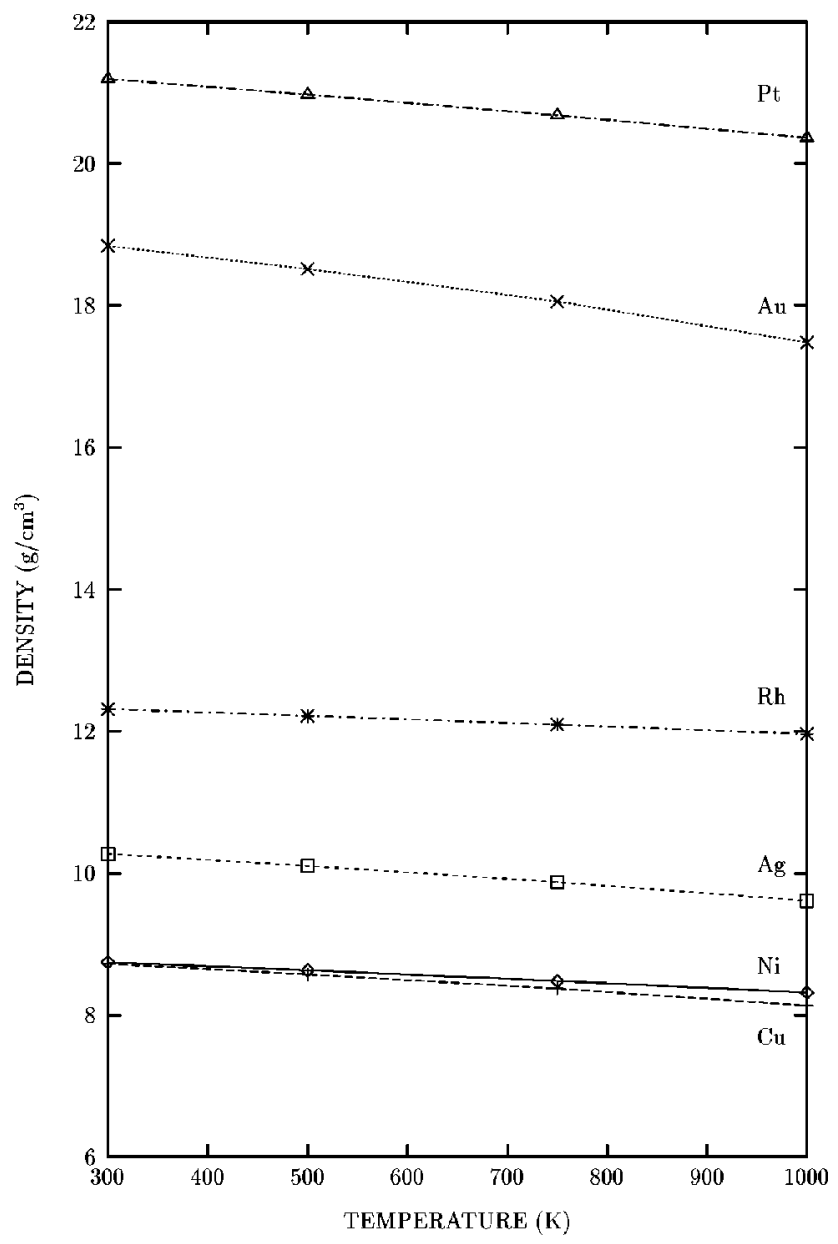

FIG. 1. Densities of $\mathrm{Ni}, \mathrm{Cu}, \mathrm{Ag}, \mathrm{Au}, \mathrm{Pt}$, and $\mathrm{Rh}$ as a function of temperature. 


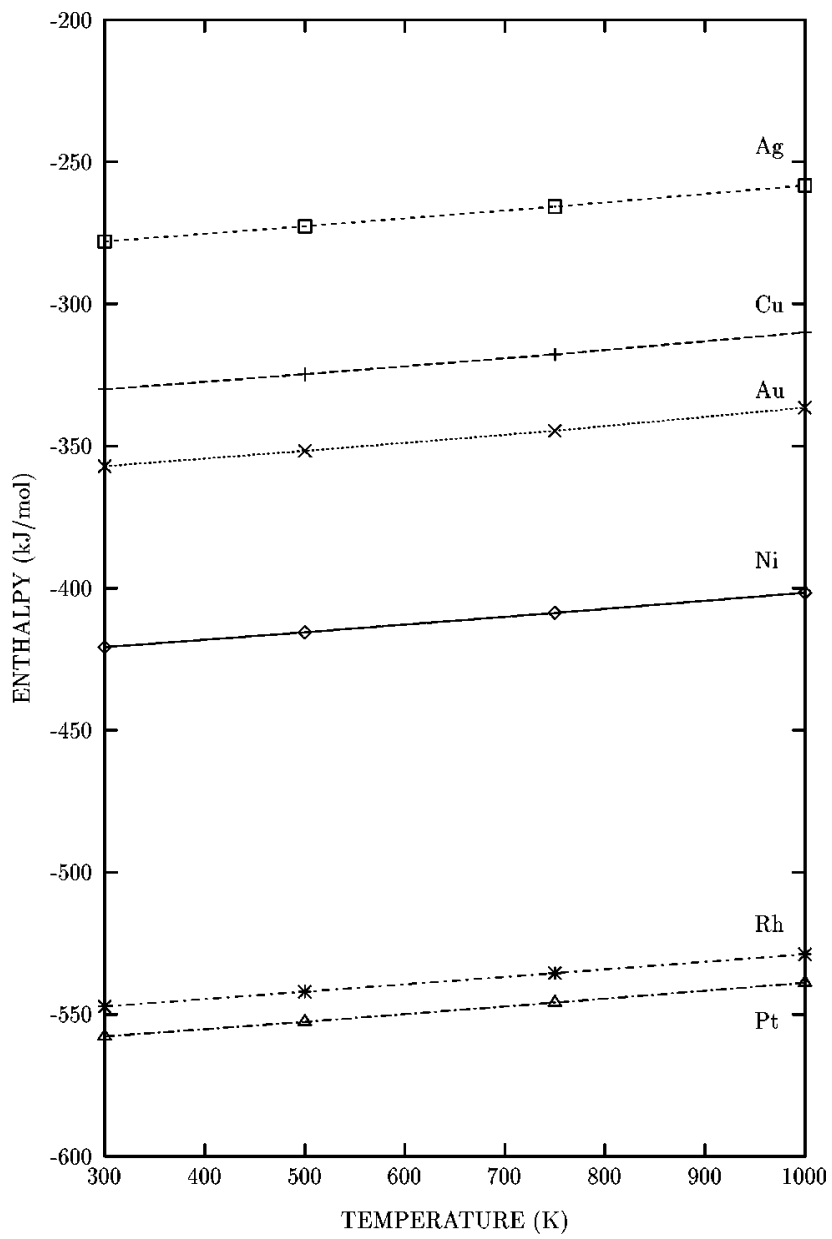

FIG. 2. Enthalpies of $\mathrm{Ni}, \mathrm{Cu}, \mathrm{Ag}, \mathrm{Au}, \mathrm{Pt}$, and $\mathrm{Rh}$ as a function of temperature.

TABLE IV. Elastic constants and bulk modulus of Ni calculated at $300,500,750$, and $1000 \mathrm{~K}$ as obtained from NVE molecular dynamics simulation after 50000 steps.

\begin{tabular}{rcccc}
\hline \hline $\begin{array}{c}T \\
(\mathrm{~K})\end{array}$ & $\begin{array}{c}C_{11} \\
(\mathrm{GPa})\end{array}$ & $\begin{array}{c}C_{12} \\
(\mathrm{GPa})\end{array}$ & $\begin{array}{c}C_{44} \\
(\mathrm{GPa})\end{array}$ & $\begin{array}{c}B \\
(\mathrm{GPa})\end{array}$ \\
\hline 300 & $213.76 \pm 0.19$ & $166.57 \pm 0.20$ & $69.77 \pm 0.21$ & $182.30 \pm 0.20$ \\
500 & $201.70 \pm 0.21$ & $159.48 \pm 0.51$ & $63.56 \pm 0.20$ & $173.55 \pm 0.41$ \\
750 & $186.05 \pm 0.66$ & $150.34 \pm 0.06$ & $55.94 \pm 0.55$ & $162.24 \pm 0.26$ \\
1000 & $169.14 \pm 1.99$ & $141.08 \pm 0.87$ & $48.29 \pm 0.28$ & $150.43 \pm 1.24$ \\
\hline \hline
\end{tabular}

TABLE V. Elastic constants and bulk modulus of $\mathrm{Cu}$ calculated at $300,500,750$, and $1000 \mathrm{~K}$ as obtained from NVE molecular dynamics simulation after 50000 steps.

\begin{tabular}{rcccr}
\hline \hline $\begin{array}{c}T \\
(\mathrm{~K})\end{array}$ & $\begin{array}{c}C_{11} \\
(\mathrm{GPa})\end{array}$ & \multicolumn{1}{c}{$\begin{array}{c}C_{12} \\
(\mathrm{GPa})\end{array}$} & $\begin{array}{c}C_{44} \\
(\mathrm{GPa})\end{array}$ & \multicolumn{1}{c}{\begin{tabular}{c}
\multicolumn{1}{c}{$\boldsymbol{B}$} \\
$(\mathrm{GPa})$
\end{tabular}} \\
\hline 300 & $153.06 \pm 0.42$ & $119.45 \pm 0.16$ & $49.35 \pm 0.27$ & $130.65 \pm 0.25$ \\
500 & $140.87 \pm 0.19$ & $112.78 \pm 0.24$ & $43.46 \pm 0.40$ & $122.14 \pm 0.23$ \\
750 & $126.46 \pm 1.06$ & $104.43 \pm 0.32$ & $36.37 \pm 1.39$ & $111.77 \pm 0.57$ \\
1000 & $109.09 \pm 0.66$ & $94.40 \pm 0.94$ & $27.92 \pm 0.65$ & $99.30 \pm 0.85$ \\
\hline \hline
\end{tabular}

TABLE VI. Elastic constants and bulk modulus of Ag calculated at $300,500,750$, and $1000 \mathrm{~K}$ as obtained from NVE molecular dynamics simulation after 50000 steps.

\begin{tabular}{ccccc}
\hline \hline $\begin{array}{c}T \\
(\mathrm{~K})\end{array}$ & $\begin{array}{c}C_{11} \\
(\mathrm{GPa})\end{array}$ & $\begin{array}{c}C_{12} \\
(\mathrm{GPa})\end{array}$ & $\begin{array}{c}C_{44} \\
(\mathrm{GPa})\end{array}$ & $\begin{array}{c}B \\
(\mathrm{GPa})\end{array}$ \\
\hline 300 & $126.95 \pm 0.23$ & $88.49 \pm 0.11$ & $50.50 \pm 0.08$ & $101.31 \pm 0.15$ \\
500 & $117.46 \pm 0.27$ & $83.45 \pm 0.13$ & $45.50 \pm 0.28$ & $94.79 \pm 0.17$ \\
750 & $104.16 \pm 0.58$ & $76.79 \pm 0.72$ & $37.75 \pm 0.33$ & $85.91 \pm 0.68$ \\
1000 & $91.88 \pm 0.86$ & $70.59 \pm 1.27$ & $31.54 \pm 0.80$ & $77.69 \pm 1.14$ \\
\hline \hline
\end{tabular}

TABLE VII. Elastic constants and bulk modulus of Au calculated at $300,500,750$, and $1000 \mathrm{~K}$ as obtained from NVE molecular dynamics simulation after 50000 steps.

\begin{tabular}{rcccr}
\hline \hline$T$ & \multicolumn{1}{c}{$C_{11}$} & \multicolumn{1}{c}{$\begin{array}{c}C_{12} \\
(\mathrm{GPa})\end{array}$} & $\begin{array}{c}C_{44} \\
(\mathrm{GPa})\end{array}$ & \multicolumn{1}{c}{$\begin{array}{c}B \\
(\mathrm{GPa})\end{array}$} \\
\hline 300 & $158.24 \pm 0.64$ & $131.56 \pm 0.02$ & $34.92 \pm 0.10$ & $140.45 \pm 0.23$ \\
500 & $141.74 \pm 0.75$ & $118.92 \pm 0.21$ & $30.08 \pm 0.56$ & $126.52 \pm 0.39$ \\
750 & $123.92 \pm 0.62$ & $107.42 \pm 0.92$ & $24.10 \pm 0.58$ & $112.92 \pm 0.82$ \\
1000 & $95.43 \pm 0.86$ & $84.78 \pm 0.16$ & $16.78 \pm 0.81$ & $88.33 \pm 0.39$ \\
\hline \hline
\end{tabular}

TABLE VIII. Elastic constants and bulk modulus of Pt calculated from 300 to $1500 \mathrm{~K}$ with $200 \mathrm{~K}$ increments as obtained from NVE molecular dynamics simulation after 50000 steps.

\begin{tabular}{rcccc}
\hline \hline $\begin{array}{c}T \\
(\mathrm{~K})\end{array}$ & $\begin{array}{c}C_{11} \\
(\mathrm{GPa})\end{array}$ & $\begin{array}{c}C_{12} \\
(\mathrm{GPa})\end{array}$ & $\begin{array}{c}C_{44} \\
(\mathrm{GPa})\end{array}$ & $\begin{array}{c}B \\
(\mathrm{GPa})\end{array}$ \\
\hline 300 & $289.63 \pm 1.02$ & $239.55 \pm 0.16$ & $65.07 \pm 0.28$ & $256.24 \pm 0.45$ \\
500 & $272.67 \pm 0.87$ & $227.11 \pm 0.77$ & $59.67 \pm 0.36$ & $242.29 \pm 0.80$ \\
700 & $256.12 \pm 1.71$ & $214.38 \pm 0.78$ & $54.15 \pm 0.59$ & $228.30 \pm 1.09$ \\
750 & $251.09 \pm 1.06$ & $211.05 \pm 0.72$ & $52.90 \pm 0.28$ & $224.34 \pm 0.84$ \\
900 & $233.28 \pm 0.40$ & $196.58 \pm 0.32$ & $49.08 \pm 0.50$ & $208.81 \pm 0.35$ \\
1000 & $227.47 \pm 2.66$ & $193.46 \pm 0.81$ & $45.50 \pm 0.50$ & $204.80 \pm 1.43$ \\
1100 & $219.39 \pm 0.80$ & $188.60 \pm 0.62$ & $44.12 \pm 1.51$ & $198.86 \pm 0.68$ \\
1300 & $200.63 \pm 2.39$ & $174.16 \pm 0.51$ & $38.78 \pm 0.55$ & $182.98 \pm 1.14$ \\
1500 & $177.28 \pm 2.46$ & $155.50 \pm 0.40$ & $31.94 \pm 1.96$ & $162.76 \pm 1.09$ \\
\hline
\end{tabular}

TABLE IX. Elastic constants and bulk modulus of Rh calculated from 300 to $1500 \mathrm{~K}$ with $200 \mathrm{~K}$ increments as obtained from NVE molecular dynamics simulation after 50000 steps.

\begin{tabular}{rcccc}
\hline \hline $\begin{array}{c}T \\
(\mathrm{~K})\end{array}$ & $\begin{array}{c}C_{11} \\
(\mathrm{GPa})\end{array}$ & $\begin{array}{c}C_{12} \\
(\mathrm{GPa})\end{array}$ & $\begin{array}{c}C_{44} \\
(\mathrm{GPa})\end{array}$ & $\begin{array}{c}B \\
(\mathrm{GPa})\end{array}$ \\
\hline 300 & $322.30 \pm 0.66$ & $223.02 \pm 0.90$ & $131.95 \pm 0.69$ & $256.11 \pm 0.82$ \\
500 & $312.03 \pm 0.69$ & $216.89 \pm 0.44$ & $124.72 \pm 0.15$ & $248.60 \pm 0.52$ \\
700 & $298.92 \pm 0.77$ & $210.23 \pm 0.78$ & $117.44 \pm 0.14$ & $239.79 \pm 0.78$ \\
750 & $295.14 \pm 0.88$ & $207.72 \pm 0.73$ & $116.27 \pm 1.27$ & $236.86 \pm 0.78$ \\
900 & $286.44 \pm 0.62$ & $203.55 \pm 0.69$ & $110.80 \pm 0.97$ & $231.17 \pm 0.67$ \\
1000 & $279.36 \pm 1.12$ & $199.07 \pm 0.71$ & $108.16 \pm 1.07$ & $225.83 \pm 0.84$ \\
1100 & $274.83 \pm 1.49$ & $197.32 \pm 0.20$ & $104.07 \pm 0.10$ & $223.15 \pm 0.63$ \\
1300 & $263.48 \pm 0.77$ & $191.06 \pm 2.16$ & $97.36 \pm 0.88$ & $215.20 \pm 1.70$ \\
1500 & $249.59 \pm 0.12$ & $184.75 \pm 1.18$ & $91.29 \pm 1.32$ & $206.36 \pm 0.83$ \\
\hline
\end{tabular}


TABLE X. Elastic constants of fcc metals in units of GPa at $300 \mathrm{~K}$. At each entry, the first number gives the MD simulation result while the second number in parantheses is the experimental value. The third number is the MD result calculated from the experimental density.

\begin{tabular}{cccc}
\hline \hline Metal & $\begin{array}{c}C_{11} \\
(\mathrm{GPa})\end{array}$ & $\begin{array}{c}C_{12} \\
(\mathrm{GPa})\end{array}$ & $\begin{array}{c}C_{44} \\
(\mathrm{GPa})\end{array}$ \\
\hline $\mathrm{Ni}$ & $213.76(250.8) 239.3$ & $166.50(150.0) 180.22$ & $69.77(123.5) 81.40$ \\
$\mathrm{Cu}$ & $153.06(168.39) 175.70$ & $119.45(121.42) 132.00$ & $49.35(75.39) 58.60$ \\
$\mathrm{Ag}$ & $126.95(123.99) 147.70$ & $88.49(93.67) 100.00$ & $50.50(46.12) 60.44$ \\
$\mathrm{Au}$ & $158.24(192.34) 191.20$ & $131.56(163.14) 151.60$ & $34.92(41.95) 47.20$ \\
$\mathrm{Pt}$ & $289.63(346.7) 323.51$ & $239.55(250.7) 259.85$ & $65.07(76.5) 78.16$ \\
$\mathrm{Rh}$ & $322.30(412.6) 340.59$ & $223.02(193.5) 232.27$ & $131.95(184.1) 139.86$ \\
\hline \hline
\end{tabular}

dynamics at the target temperature. In order to show the behavior of Sutton-Chen potentials at elevated temperatures; the results of density and enthalpy are plotted at temperatures 300, 500, 750 and $1000 \mathrm{~K}$ in Figs. 1 and 2. The extra data for $\mathrm{Pt}$ and $\mathrm{Rh}$ at temperatures 700, 900, 1100, 1300, and $1500 \mathrm{~K}$ are coming from the calculations of Pt-Rh alloys. ${ }^{3}$ In Table II, the experimental and simulation results of the densities are shown for 0 and $300 \mathrm{~K}$. Simulation results show approximately $1.0 \%$ deviation from the experimental values at 0 and $2.0 \%$ deviation at $300 \mathrm{~K}$. The percent change in the lattice parameter at each temperature (the lattice parameter at $300 \mathrm{~K}$ is used as the reference) for $\mathrm{Ni}, \mathrm{Cu}, \mathrm{Ag}, \mathrm{Au}$ are given in Table III. Pt and Rh results are discussed in Ref. 3. As a concluding remark, it can be said that as the temperature increases the deviation from the experimental values increases.

In Tables IV-IX, the results of the calculations of the elastic constants and bulk moduli of $\mathrm{Ni}, \mathrm{Cu}, \mathrm{Ag}, \mathrm{Au}, \mathrm{Pt}$, and Rh obtained from NVE simulations of 50000 steps are presented. Elastic constants are calculated in the temperature range between 300 to $1000 \mathrm{~K}$. In the calculations at each concentration and at each temperature first the zero-strain state of the system is determined by performing constanttemperature and constant-stress simulations. In determining the elastic constants this reference state is used in constanttemperature, constant-volume simulations of 50000 steps for each state point. Comparison with experimental results at

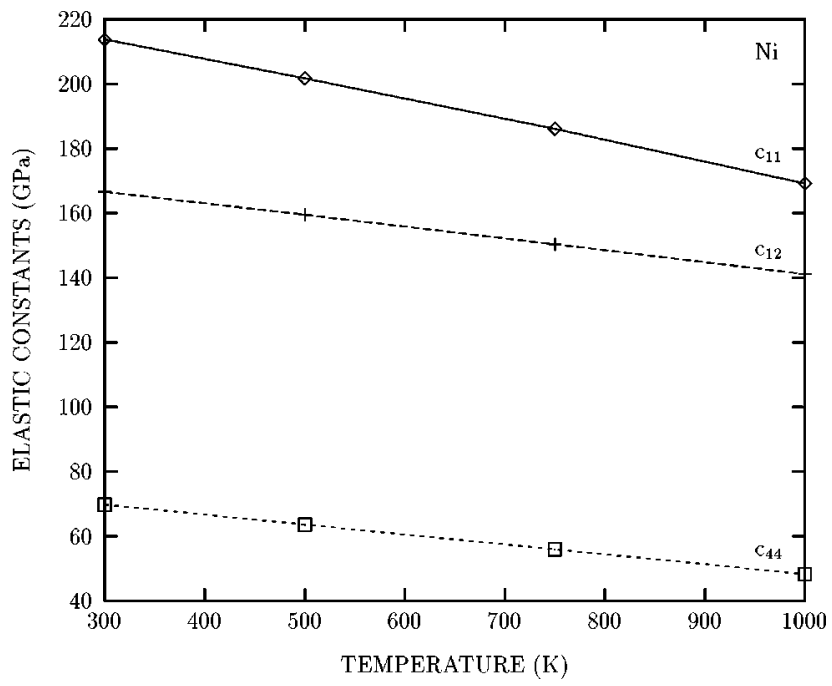

FIG. 3. Elastic constants of $\mathrm{Ni}$ as a function of temperature.
$300 \mathrm{~K}$ is shown in Table $\mathrm{X}$. The ratio of $C_{12} / C_{44}$ is 2.38 for $\mathrm{Ni}, 2.42$ for $\mathrm{Cu}, 1.75$ for $\mathrm{Ag}, 3.76$ for $\mathrm{Au}, 3.68$ for $\mathrm{Ph}$, and 1.69 for Rh. In Fig. 3, the variations of elastic constants with respect to temperature is given for $\mathrm{Ni}$. The change in the bulk moduli of these metals by heating is shown in Fig. 4. The simulation values of the bulk moduli at $1000 \mathrm{~K}$ are the fingerprints for the melting temperature of these metals. The bulk modulus is higher for higher melting temperature. The elastic constants results show that the crystals are elastically stable since the stability conditions $C_{44}>0, C_{11}>0$, and $C_{11}>C_{12}$ are satisfied and thermal softening behavior is observed as the temperature is increased.

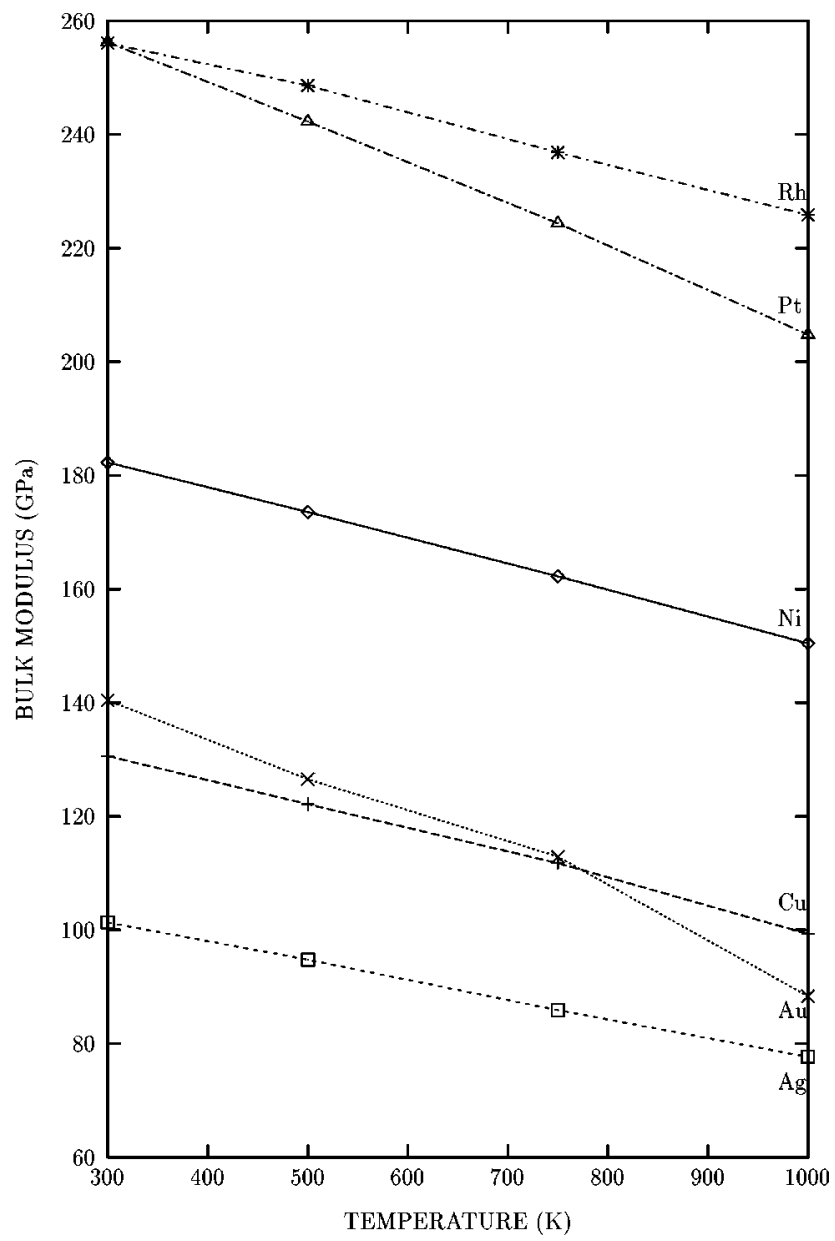

FIG. 4. Bulk moduli of $\mathrm{Ni}, \mathrm{Cu}, \mathrm{Ag}, \mathrm{Au}, \mathrm{Pt}$, and $\mathrm{Rh}$ as a function of temperature. 
TABLE XI. Elastic constants of fcc metals in units of GPa at $0 \mathrm{~K}$. At each entry, the first number gives the experimental result while the second number in round brackets is the static calculation of Sutton and Chen (Ref. 1). Third number is the MD result.

\begin{tabular}{lccc}
\hline \hline Metal & $\begin{array}{c}C_{11} \\
(\mathrm{GPa})\end{array}$ & $\begin{array}{c}C_{12} \\
(\mathrm{GPa})\end{array}$ & $\begin{array}{c}C_{44} \\
(\mathrm{GPa})\end{array}$ \\
\hline $\mathrm{Ni}$ & $261.13(230.69) 231.37$ & $150.59(177.82) 176.59$ & $131.36(80.10) 79.08$ \\
$\mathrm{Cu}$ & $176.22(169.81) 168.77$ & $124.96(129.76) 128.77$ & $81.70(57.87) 57.68$ \\
$\mathrm{Ag}$ & $131.36(140.98) 140.98$ & $97.72(96.12) 96.02$ & $51.26(59.27) 59.10$ \\
$\mathrm{Au}$ & $187.43(179.42) 179.74$ & $155.39(147.38) 147.49$ & $44.86(41.64) 42.11$ \\
$\mathrm{Pt}$ & $357.25(313.99) 314.02$ & $254.72(257.92) 257.70$ & $76.90(73.69) 73.54$ \\
$\mathrm{Rh}$ & $421.33(339.62) 340.63$ & $192.24(232.29) 232.24$ & $193.84(142.58) 142.73$ \\
\hline \hline
\end{tabular}

It is important to note the following for a realistic assessment of the performance of the input potential. It seems that the density at zero stress is consistently lower than the experimental results. To study this discrepancy, we have done density simulations at low temperatures $(0 \mathrm{~K})$. The results are shown in Table II. The discrepancy is still present. This can also be seen in the linear expansion data given in Table III.

The low-temperature values of the elastic constants calculated at $0 \mathrm{~K}$ are given in Table XI. Our simulation results are closer to the Sutton-Chen values than the experimental values.

The elastic constants obtained by using the experimental density at $300 \mathrm{~K}$ are compared with experimental and simulation values obtained by using the simulated density in Table X. As it is seen from this table, there is no consistent improvement.
Since the parametrization of these potentials is based on the bulk properties at $0 \mathrm{~K}$, it can describe the temperaturedependent behavior of the solid only qualitatively. As an overall conclusion we can state that the problem seems to be originating from the potential parameters used rather than the NPT MD method which works quite well in determining the zero strain state $h_{0}$ of the system at each concentration and at each temperature.

\section{ACKNOWLEDGMENTS}

This research was supported by the Scientific and Technical Research Council of Turkey (TUBITAK) through Project No. TBAG 1592 and by the Middle East Technical University Research Fund through Project No. AFP-96-0105-03.
${ }^{1}$ A. P. Sutton, Philos. Mag. Lett. 61, 139 (1990).

${ }^{2}$ H. Rafii-Tabar and A. P. Sutton, Philos. Mag. Lett. 63, 217 (1991).

${ }^{3}$ G. Dereli, T. Çă̆ın , M. Uludoğan, and M. Tomak, Philos. Mag. Lett. 75, 209 (1997).

${ }^{4}$ S. Dalgiç, S. Dalgiç, G. Dereli, and M. Tomak, Phys. Rev. B 50, 113 (1994).

${ }^{5}$ J. K. Norskov, Phys. Rev. B 26, 2875 (1982).

${ }^{6}$ M. S. Daw and M. I. Baskes, Phys. Rev. B 29, 6443 (1984).

${ }^{7}$ M. W. Finnis and J. F. Sinclair, Philos. Mag. A 50, 45 (1984).

${ }^{8}$ G. J. Ackland and M. W. Finnis, Philos. Mag. A 54, 301 (1986).

${ }^{9}$ D. D. Koleske and S. J. Sibener, Surf. Sci. 290, 179 (1993).

${ }^{10}$ R. M. Lyndenbell, Surf. Sci. 259, 129 (1991).

${ }^{11}$ J. Uppenbrink, D. J. Wales, A. I. Kirkland, D. A. Jefferson, and J. Urban, Philos. Mag. B 65, 1079 (1992).
${ }^{12}$ K. D. Hammonds and R. M. Lyndenbell, Surf. Sci. 278, 437 (1992).

${ }^{13}$ B. D. Todd and R. M. Lyndenbell, Surf. Sci. 281, 191 (1993).

${ }^{14}$ B. D. Todd and R. M. Lyndenbell, Surf. Sci. 328, 170 (1995).

${ }^{15}$ K. D. Shiang, Phys. Lett. A 180, 444 (1993).

${ }^{16}$ D. J. Wales and L. J. Munro, J. Phys. Chem. 100, 2053 (1996).

${ }^{17}$ T. Çă̆ın and J. R. Ray, Phys. Rev. A 37, 247 (1988); Phys. Rev. B 37, 699 (1988); 38, 7940 (1988); T. Çağın and B. M. Pettitt, 39, 12484 (1989); T. Çağın and J. R. Ray, Phys. Rev. A 37, 4510 (1998).

${ }^{18}$ H. C. Andersen, J. Chem. Phys. 72, 2384 (1980).

${ }^{19}$ M. Parrinello and A. Rahman, Phys. Rev. Lett. 45, 1196 (1980).

${ }^{20}$ Shiuchi Nosé, J. Chem. Phys. 81, 511 (1984).

${ }^{21}$ W. G. Hoover, Phys. Rev. A 31, 1695 (1985).

${ }^{22}$ T. Çă̆ın and B. M. Pettitt, Mol. Phys. 72, 169 (1991); Mol. Simul. 6, 5 (1991). 